\title{
Nitro-Grela-type complexes containing iodides - robust and selective catalysts for olefin metathesis under challenging conditions
}

\author{
Andrzej Tracz ${ }^{1,2}$, Mateusz Matczak ${ }^{1}$, Katarzyna Urbaniak ${ }^{1}$ and Krzysztof Skowerski ${ }^{* 1}$
}

\author{
Full Research Paper \\ Address: \\ ${ }^{1}$ Apeiron Synthesis SA, Duńska 9, 54-427 Wrocław, Poland and \\ ${ }^{2}$ Department of Bioorganic Chemistry, Faculty of Chemistry, Wroclaw \\ University of Technology, Wybrzeże Wyspańskiego 27, 50-370 \\ Wrocław, Poland \\ Email: \\ Krzysztof Skowerski* - krzysztof.skowerski@apeiron-synthesis.com \\ * Corresponding author \\ Keywords: \\ green solvents; macrocyclization; metathesis; ruthenium
}

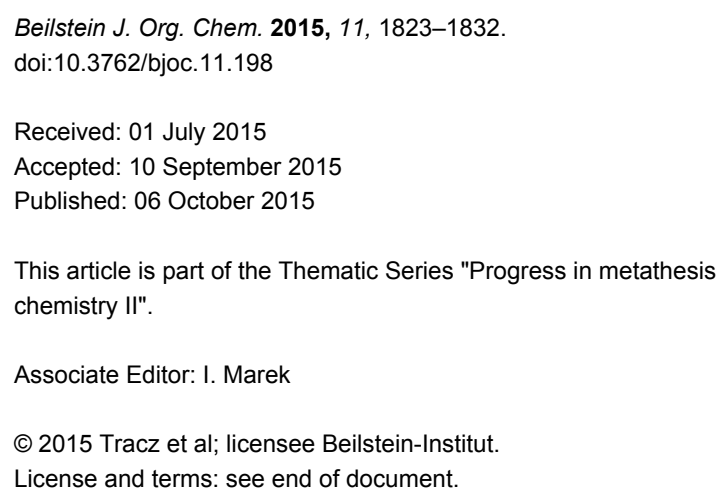

\begin{abstract}
Iodide-containing nitro-Grela-type catalysts have been synthesized and applied to ring closing metathesis (RCM) and cross metathesis (CM) reactions. These new catalysts have exhibited improved efficiency in the transformation of sterically, nondemanding alkenes. Additional steric hindrance in the vicinity of ruthenium related to the presence of iodides ensures enhanced catalyst stability. The benefits are most apparent under challenging conditions, such as very low reaction concentrations, protic solvents or with the occurrence of impurities.
\end{abstract}

\section{Introduction}

Olefin metathesis $(\mathrm{OM})$ is a mild and versatile catalytic method which allows the formation of carbon-carbon double bonds [1]. Understanding the key events in ruthenium-catalyzed olefin metathesis [2] and developing efficient and selective catalysts [3] provides opportunities for industrial applications of this technology. In many cases, however, the achievement of high turn over numbers (TONs) requires tedious purification of starting materials and solvents. New catalysts with increased efficiency and selectivity, especially under challenging conditions, are therefore of high interest. Currently, the second generation Hoveyda-type catalysts, such as HII [4], A [5], B [6], and
C [7] are considered to be the most versatile tool for OM (Figure 1).

Modifications of ligands permanently bound to the ruthenium center appear to be the most efficient methods for altering the catalyst properties. Great improvement of catalyst efficiency in the transformation of sterically non-demanding alkenes have been achieved by the replacement of the classical SIMes ligand with the bulkier SIPr ligand (Scheme 1) [8,9]. Metathesis catalysts with even larger NHC ligands have also been reported, but their syntheses require additional steps because the necessary 


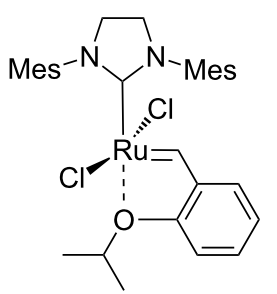

HII, general application

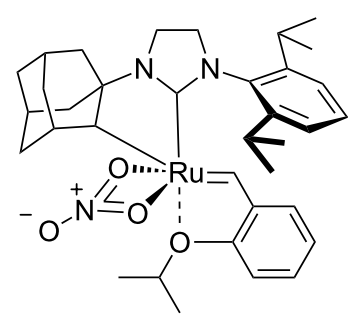

A, Z-selective metathesis

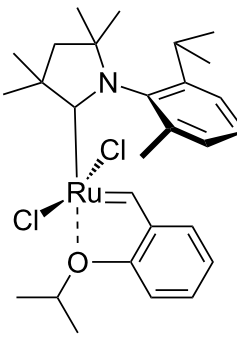

B, ethenolysis

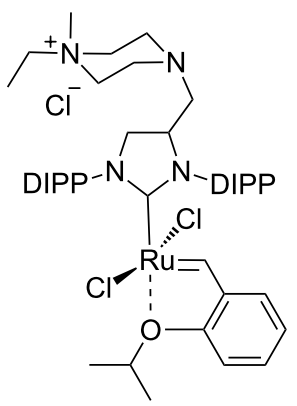

C, heterogeneous metathesis

Figure 1: The diversity of Hoveyda-type complexes (Mes - 2,4,6-trimethylphenyl, DIPP - 2,6-diisopropylphenyl).

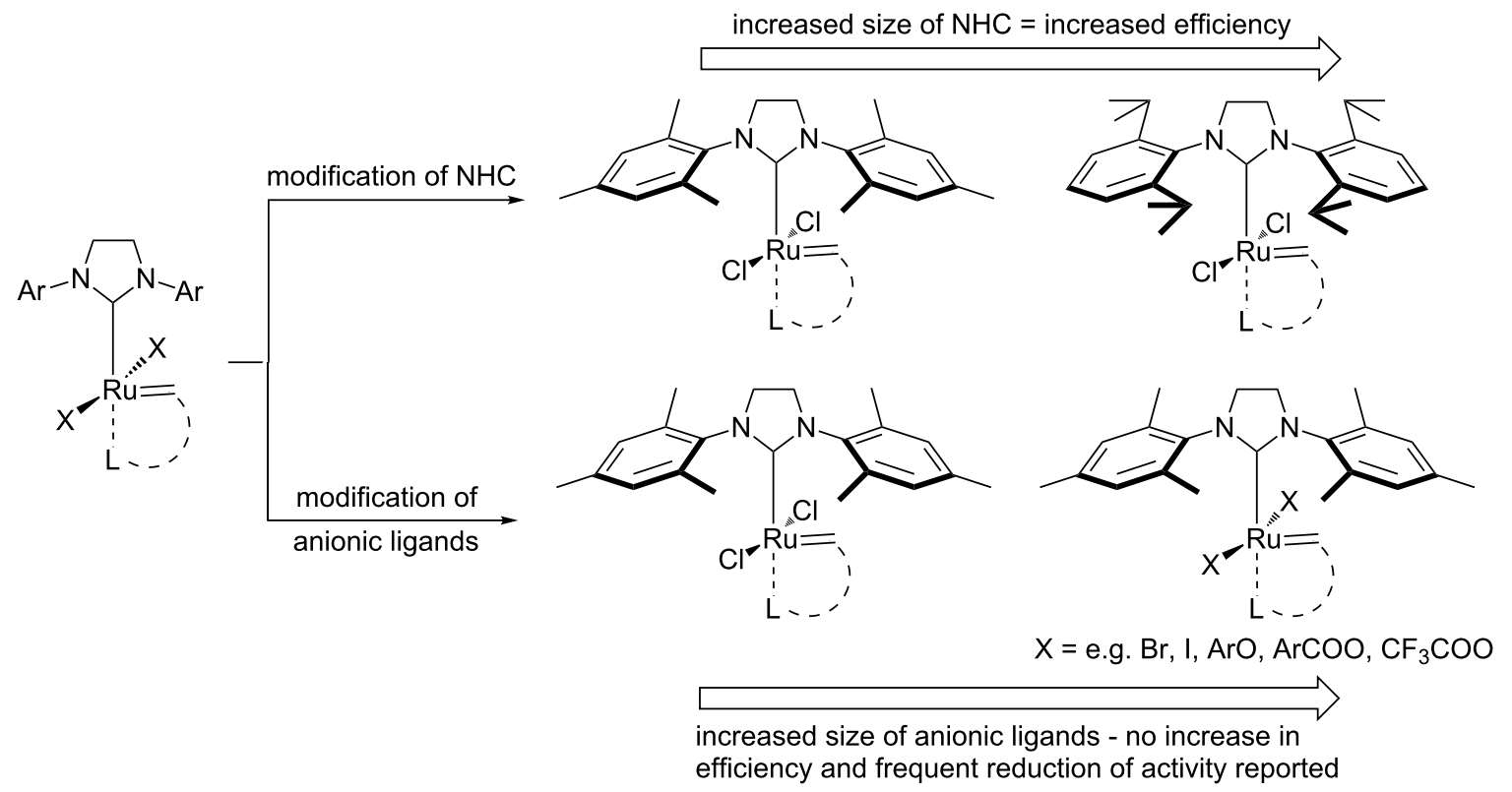

Scheme 1: Modifications of the $2^{\text {nd }}$ generation alkylidene complexes.

anilines - the starting materials for the preparation of NHCs precursors - are not commercially available [10,11]. Up until now, there had been no disclosures of increased catalyst efficiency caused by the exchange of chlorides with larger anionic ligands. Grubbs et al. showed that the exchange of chlorides for bromides or iodides in the second generation Grubbs' catalysts facilitated the initiation, but reduced the propagation rate and eventually provided no overall improvement [12]. More recently Slugove et al. synthesized bromo- and iodo- analogues of HII, but no improvement was noted [13-15]. Moreover, the presence of iodide ligands reduced initiation rates for Hoveyda second generation complex bearing iodides (HII-I2) in ringclosing metathesis (RCM). Similarly, Schrodi and colleagues did not find any advantages for halide exchanged Hoveyda-type complexes in cross metathesis of methyl oleate with ethylene [16]. Complexes containing iodide lead to products of asymmetric OM with better enantio- and diastereoselectivity, but this came at the price of lower activity [17]. In the past few years the replacement of chloride ligands created the first $Z$-selective catalysts [18-21]. Their efficiency, however, is noticeably lower than that observed for classical complexes. The second generation indenylidene catalysts with phosphite ligand (frequently reported as "Cazin-type catalysts") bearing mixed chloride-fluoride or difluoride anionic ligands were also reported very recently [22]. The former catalyst exhibited thermal stability and efficiency comparable with the original complex having two chlorides, while the difluoride catalyst showed low catalytic activity. Finally, alternative anionic 
ligands have been used in order to heterogenize catalysts, which resulted in the formation of materials with reduced activity and efficiency $[23,24]$.

It is well recognized that the benzylidene ligand structure strongly influences initiation rates for Hoveyda-type catalysts [25]. As a consequence of the "boomerang effect", which was recently strongly supported by Fogg et al. [26], the benzylidene ligand also most likely affects propagation rates.

In our search for active, more robust and selective catalysts, we synthesized iodide-containing nitro-Grela type catalysts. A synergistic effect of the ligands was sought: the nitro-substituted benzylidene ligand was expected to ensure fast initiation, while the bulky iodides were anticipated to provide additional stabilization of the active species.

\section{Results and Discussion}

The new iodide-containing catalysts, nG-I2 and nG-SIPr-I2, were prepared with a $93 \%$ yield from commercially available complexes, $\mathbf{n G}$ and $\mathbf{n G - S I P r}$, and with the use of potassium iodide as the iodide anions source (Scheme 2). In the synthesis of both catalysts, the isolated material contained $99 \%$ of the expected diiodo catalyst and $1 \%$ of the "mixed halogen" complex, which was identified by field desorption mass spectrometry (FD-MS) and quantified by ${ }^{1} \mathrm{H}$ NMR.

In order to determine the differences in the initiation rate between the new and parent complexes, we ran the RCM of diethyl diallylmalonate (DEDAM) in toluene $\left(\mathrm{C}^{0}{ }_{\text {DEDAM }} 0.2 \mathrm{M}\right)$ at a relatively low temperature $\left(18{ }^{\circ} \mathrm{C}\right)$ with only $0.15 \mathrm{~mol} \%$ of the catalyst (Figure 2). The nG-I2 catalyst initiated slightly more slowly than the parent $\mathbf{n G}$, but was more stable and after $1 \mathrm{~h}$ gave greater than a $10 \%$ better conversion of the substrate as indicated in Figure 2. The catalytic performance of nG-I2 was almost identical to that observed for nG-SIPr, suggesting that the exchange of chloride with iodide can - at least for some substrates - provide similar catalyst stabilization as the intro- duction of a bulky NHC ligand. In the case of the most sterically crowded nG-SIPr-I2, initiation was delayed, but a very fast reaction propagation was observed. This catalyst was the most stable and efficient among all tested complexes.
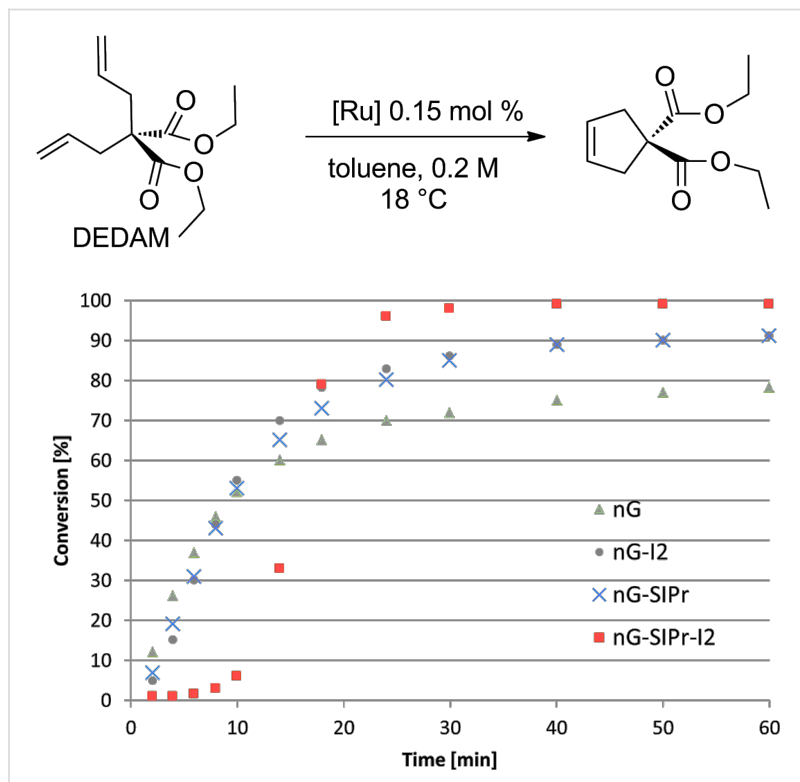

Figure 2: Reaction profiles for RCM of DEDAM; toluene, $0.2 \mathrm{M}, 18^{\circ} \mathrm{C}$, [Ru] $0.15 \mathrm{~mol} \%$; conversion determined by GC.

To gain more information about the scope of application of the obtained catalysts, we carried out a set of standard RCM and CM transformations (Table 1 and Table 2). The reactions were performed in dry, degassed toluene, at $70{ }^{\circ} \mathrm{C}$ with varied catalyst loadings to demonstrate differences in their efficiencies.

The efficiency pattern observed in RCM of DEDAM was confirmed in the synthesis of five- to seven-membered, disubstituted heterocycles (Table 1, entries 1-3). Both nG-I2 and nG-SIPr-I2 proved to be sensitive to the steric bulk in close proximity to the double bond. Thus, RCM with substrate 7 having one double bond terminally substituted with the phenyl
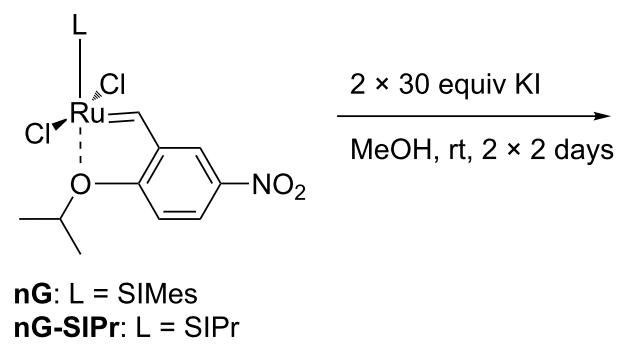
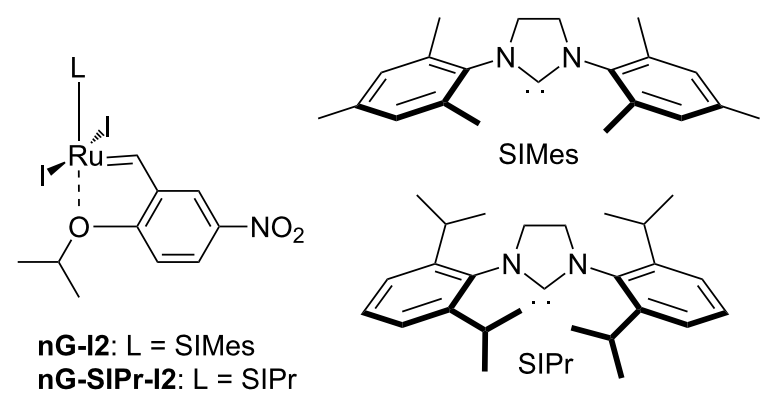


\begin{tabular}{|c|c|c|c|c|}
\hline Entry & Substrate & Product & Catalyst (mol \%) & GC Conversion [\%] \\
\hline \multirow{4}{*}{1} & 15 & Ts & nG $(0.0025)$ & 32 \\
\hline & & & nG-12 (0.0025) & 72 \\
\hline & & & nG-SIPr (0.0025) & 85 \\
\hline & 1 & 2 & nG-SIPr-12 (0.0025) & 95 \\
\hline \multirow{4}{*}{2} & Ts & Ts & nG (0.003) & 67 \\
\hline & & & nG-12 (0.003) & 91 \\
\hline & & & nG-SIPr (0.003) & 90 \\
\hline & 3 & 4 & nG-SIPr-12 (0.003) & 97 \\
\hline \multirow{4}{*}{3} & & Ts & nG $(0.0075)$ & 57 \\
\hline & & & nG-12 (0.0075) & 87 \\
\hline & & & nG-SIPr (0.0075) & 86 \\
\hline & 5 & 6 & nG-SIPr-I2 (0.0075) & 94 \\
\hline \multirow{4}{*}{4} & $s$ & & nG (0.015) & 89 \\
\hline & & & nG-12 (0.015) & 82 \\
\hline & & & nG-SIPr (0.015) & 95 \\
\hline & 7 & 2 & nG-SIPr-12 (0.015) & 47 \\
\hline \multirow{4}{*}{5} & Ts & Ts & nG (0.05) & 93 \\
\hline & & & nG-I2 (0.05) & 79 \\
\hline & & & nG-SIPr (0.05) & 99 \\
\hline & 8 & 9 & nG-SIPr-12 (0.05) & 75 \\
\hline \multirow{4}{*}{6} & & & nG (0.04) & 80 \\
\hline & & & nG-12 (0.04) & 94 \\
\hline & & & nG-SIPr (0.04) & 99 \\
\hline & & & nG-SIPr-12 (0.04) & 94 \\
\hline
\end{tabular}

aToluene, $0.2 \mathrm{M}, 70^{\circ} \mathrm{C}, 2 \mathrm{~h}$.

ring as well as the formation of the trisubstituted heterocycle 9 proceeded better with chloride-containing catalysts. When proline derivative $\mathbf{1 0}$ was used, the diiodo catalysts performed better than $\mathbf{n G}$ but slightly worse than nG-SIPr.

As outlined in Table 2, all tested catalysts were similarly effective in CM of methyl undecenoate 12 with cis-1,4-diacetoxy-2butene (13), but parent dichloro complexes provided smaller quantities of dimerization product of $\mathbf{1 2}$. In CM of $\mathbf{1 2}$ with electron deficient methyl acrylate $\mathbf{1 5}$, diiodo derivatives were significantly less efficient and provided much more dimer of $\mathbf{1 2}$. Apparently nG-I2 and nG-SIPr-I2 can perform noticeably better than parent dichloro complexes only in metathesis of sterically non-demanding substrates. With this knowledge, we decided to test their applicability under conditions which require high stability of the active species. Macrocyclization of dienes having low effective molarity provides access to a number of valuable musk-like compounds [27,28]. This type of transformation must be carried out at a very low concentration (usually $<10 \mathrm{mM}$ ) in order to avoid formation of oligomeric/ polymeric byproducts. Moreover, high temperature is required to complete the reaction in an acceptably short time. Therefore, a very stable and efficient catalyst is required to perform macrocyclization at reasonable loadings. The additional challenge related to high dilutions is the efficient removal of ethylene, which can be especially difficult on a large scale. Accordingly, the optimal catalyst for macrocyclization should form stable active species (usually ruthenium methylidenes), but it should also exhibit high preference of productive metathesis over unproductive metathesis. 


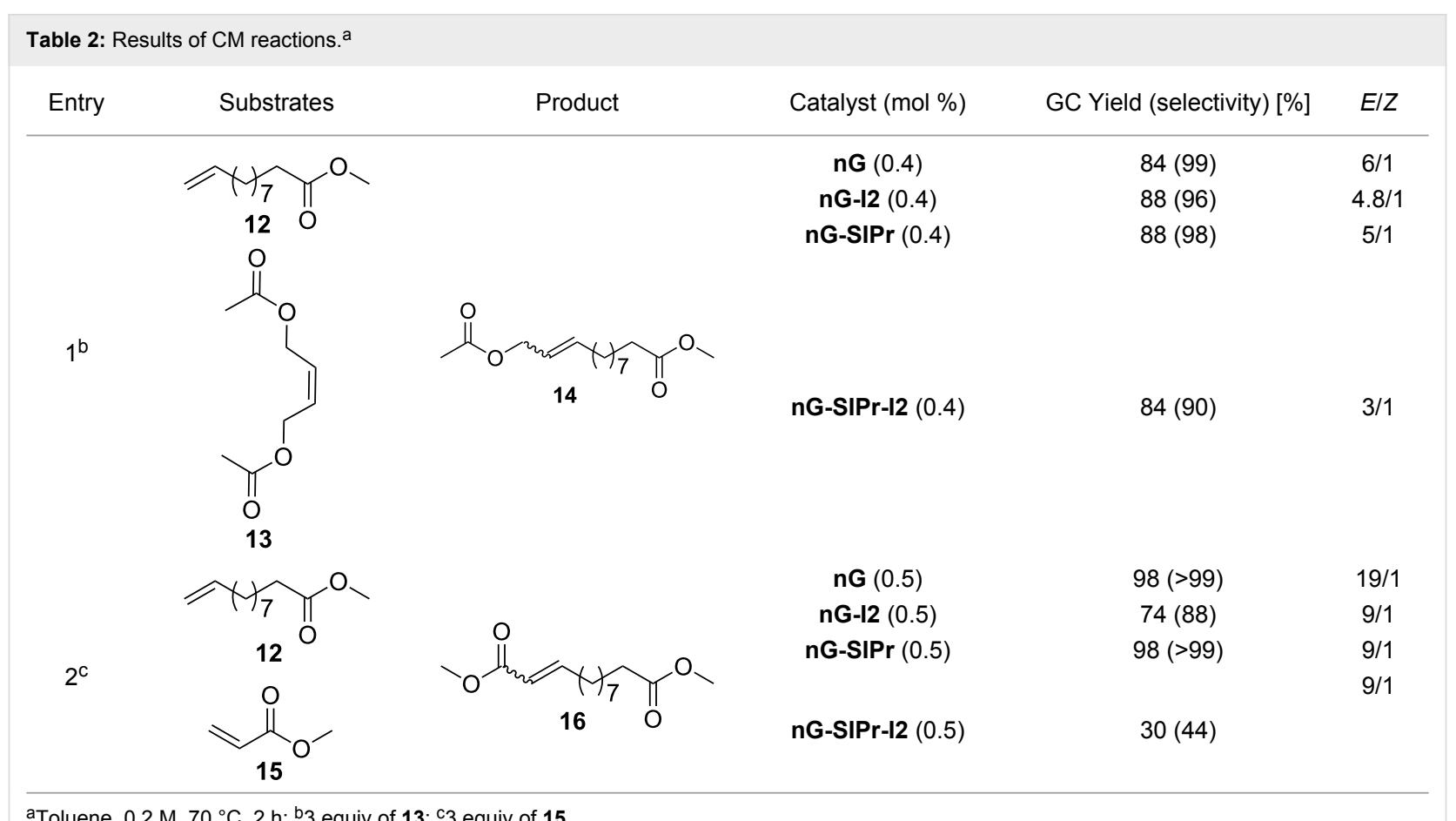

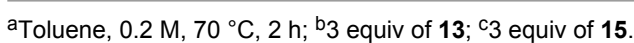

\section{Experiments with ethylene}

To gain more information about the behavior of tested catalysts in the presence of ethylene, we performed two experiments. In the first test, $100 \mathrm{ppm}$ of each catalyst was stirred for 45 minutes at $25^{\circ} \mathrm{C}$ in an ethylene atmosphere [29,30]. During that period, ruthenium methylidenes were generated and involved in the unproductive metathesis of ethylene (Figure 3). Subsequently, the atmosphere was changed to argon and the substrate $1\left(\mathrm{C}^{0}{ }_{1} 0.05 \mathrm{M}\right)$ was added. To our surprise, ethylene pre-treatment had the strongest negative effect on the most sterically crowded nG-SIPr-I2, which in our initial tests showed the highest efficiency in RCM of $\mathbf{1}$. In contrast, nG-I2 turned out to be the least sensitive to ethylene. Both dichloro complexes showed similar levels of stability. These results suggest that most stable ruthenium methylidenes were generated from nG-I2.

Next, the RCM of $\mathbf{1}$ was carried out under ethylene atmosphere which increases the probability of unproductive events (Figure 4). In this setup, the efficiency of catalysts decreased in the following order: nG-I2 = nG-SIPr-I2 > nG-SIPr $>$ nG. Good conversion obtained with nG-SIPr-I2 indicated high preference of this catalyst toward productive RCM over nonproductive metathesis. This observation partially explains the high efficiency of this catalyst obtained in RCM of $\mathbf{1}$ under conventional conditions. On the other hand, fast initiation of nG-SIPr-I2 under ethylene suggests that in the first catalytic turn-over, the small molecule of ethylene is coordinated to the ruthenium generating highly active methylidene species.

\section{Macrocyclization reactions}

As model substrates for macrocyclization we choose esters 17 and 18 which are metathesized to the 16- and 14- membered lactones. The RCM was run in toluene, at $70{ }^{\circ} \mathrm{C}$ and at $5 \mathrm{mM}$ concentration; the catalysts were added in 10 portions with 7 minutes intervals. The 16-membered lactone 19 was synthesized with the catalyst loading of $0.3 \mathrm{~mol} \%$ (Table 3, entries $1-4)$. The highest yield (91\%) along with good selectivity (93\%) was obtained with nG-I2 while only a 54\% yield and rather poor selectivity $(70 \%)$ was observed for $\mathbf{n G}$. Low selectivity of the reaction promoted by $\mathbf{n G}$ was the result of the formation of $13 \%$ of GC-observable byproducts (originated from double bond isomerization and ring contraction) as well as $10 \%$ of oligomeric/polymeric byproducts. The nG-SIPr-I2 was more efficient than nG-SIPr, but the difference was not as striking in this pair ( $85 \%$ and $69 \%$ of yield, respectively). The same efficiency profile was observed in the synthesis of 14-membered 20, which was carried out with the catalyst loading of $0.2 \mathrm{~mol} \%$ (Table 3, entries 9-12). In this transformation each catalyst formed significant amounts of oligomeric/polymeric byproducts. Interestingly, we noticed a strong dependence of the catalyst efficiency on the argon flow over the reaction mixture which indicates the high importance of the ethylene removal in this type of RCM. The high stability of ruthenium 


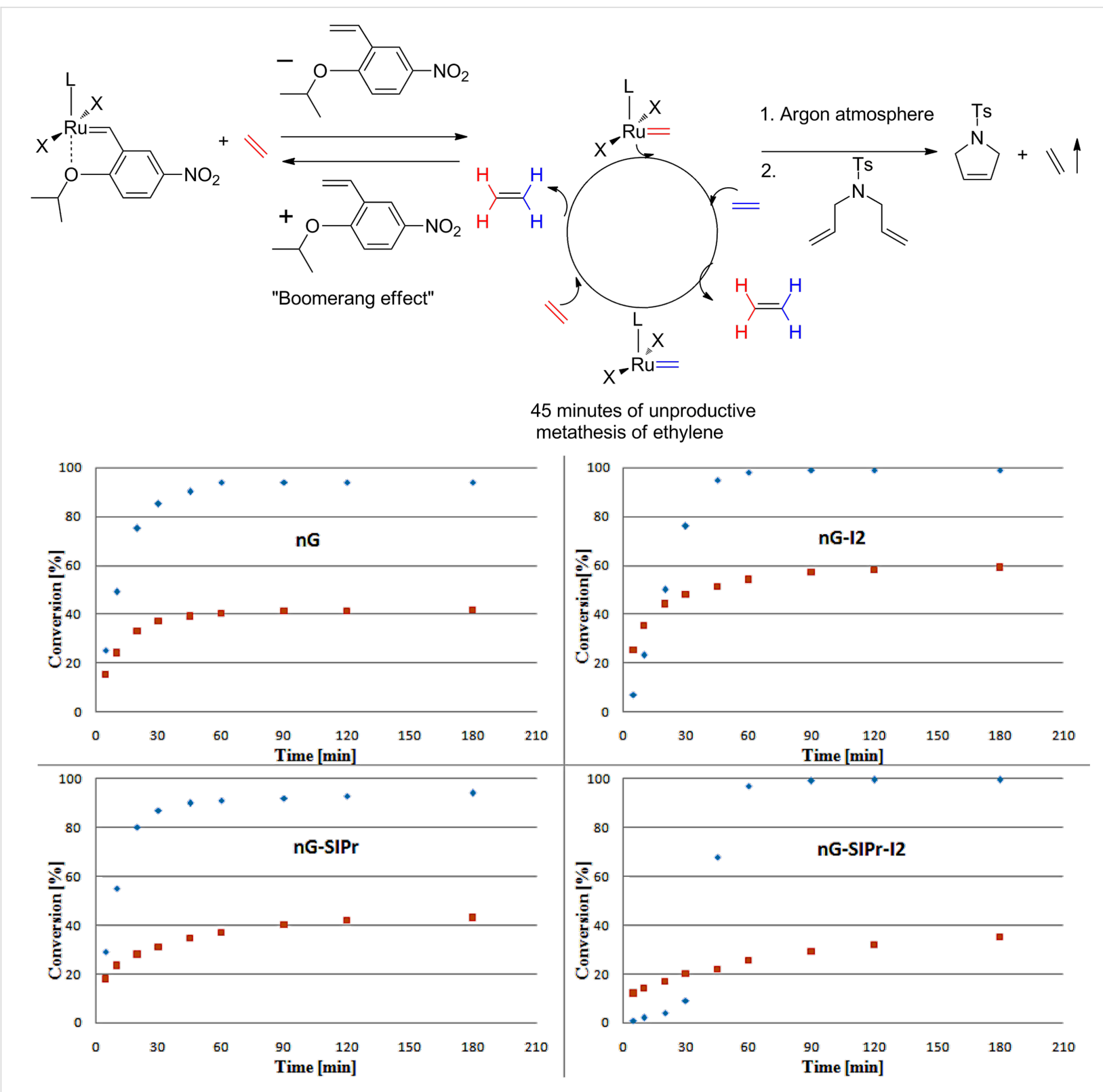

Figure 3: RCM of 1 (toluene, $0.05 \mathrm{M}, 25^{\circ} \mathrm{C}$, [Ru] $0.01 \mathrm{~mol} \%$ ); blue diamonds - original (pre)catalysts; red squares - complexes pretreated with ethylene for 45 minutes.

methylidenes generated from nG-I2 proved to be of great importance when macrocyclizations were run without active removal of ethylene (no flow of argon over the reaction mixture). In these conditions, which simulate the difficult removal of ethylene on large scale processes, nG-I2 delivered expected products with fair yields $(77 \%$ and $57 \%$ of $\mathbf{1 9}$ and $\mathbf{2 0}$, respectively) while other catalysts demonstrated less than a $10 \%$ yield.

\section{Metathesis in ACS-grade and "green" solvents}

Our continuous interest in the development of more sustainable, environmentally and user-friendly olefin metathesis has recently inspired us to test a range of commercially available, classical ruthenium initiators in ACS grade solvents under air [31]. For this study we choose substrate $\mathbf{1}$, which is highly prone to nonmetathesis reactions, namely isomerization and cycloisomerization. The result we found is that esters constitute exeptionally good solvents for RCM and CM. Conversely, application of ACS grade alcohols, ethers and toluene in many cases dramatically reduced catalyst efficiency and selectivity. It was particularly noticeable in isopropanol, in which only Hoveyda-Grubbs type complexes bearing a SIPr ligand provided expected products with $80-88 \%$ yields $\left(0.25 \mathrm{~mol} \%\right.$ of catalyst, 40 or $\left.70{ }^{\circ} \mathrm{C}\right)$. The catalysts containing a less sterically crowded SIMEs ligand 
<smiles>[X][R]([X])(I)Oc1ccc([N+](=O)[O-])cc1OC(C)C</smiles><smiles>C=CCN(C)CCCC</smiles><smiles>C=CC(CC)CCCC(C)CC</smiles>

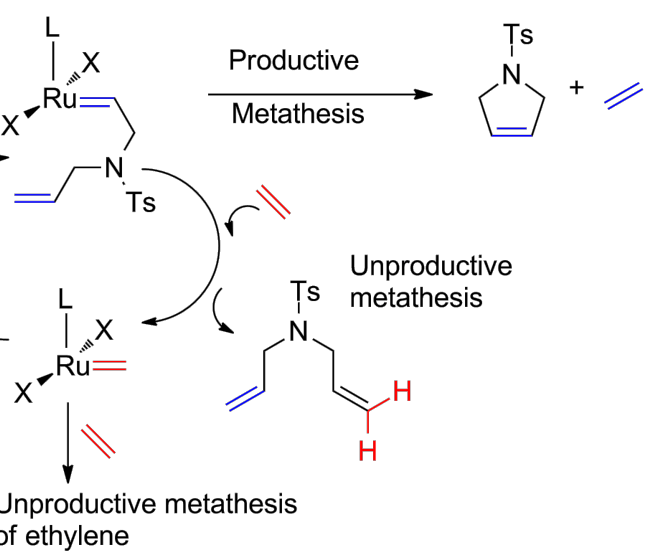<smiles>C=C[CH2+]</smiles>
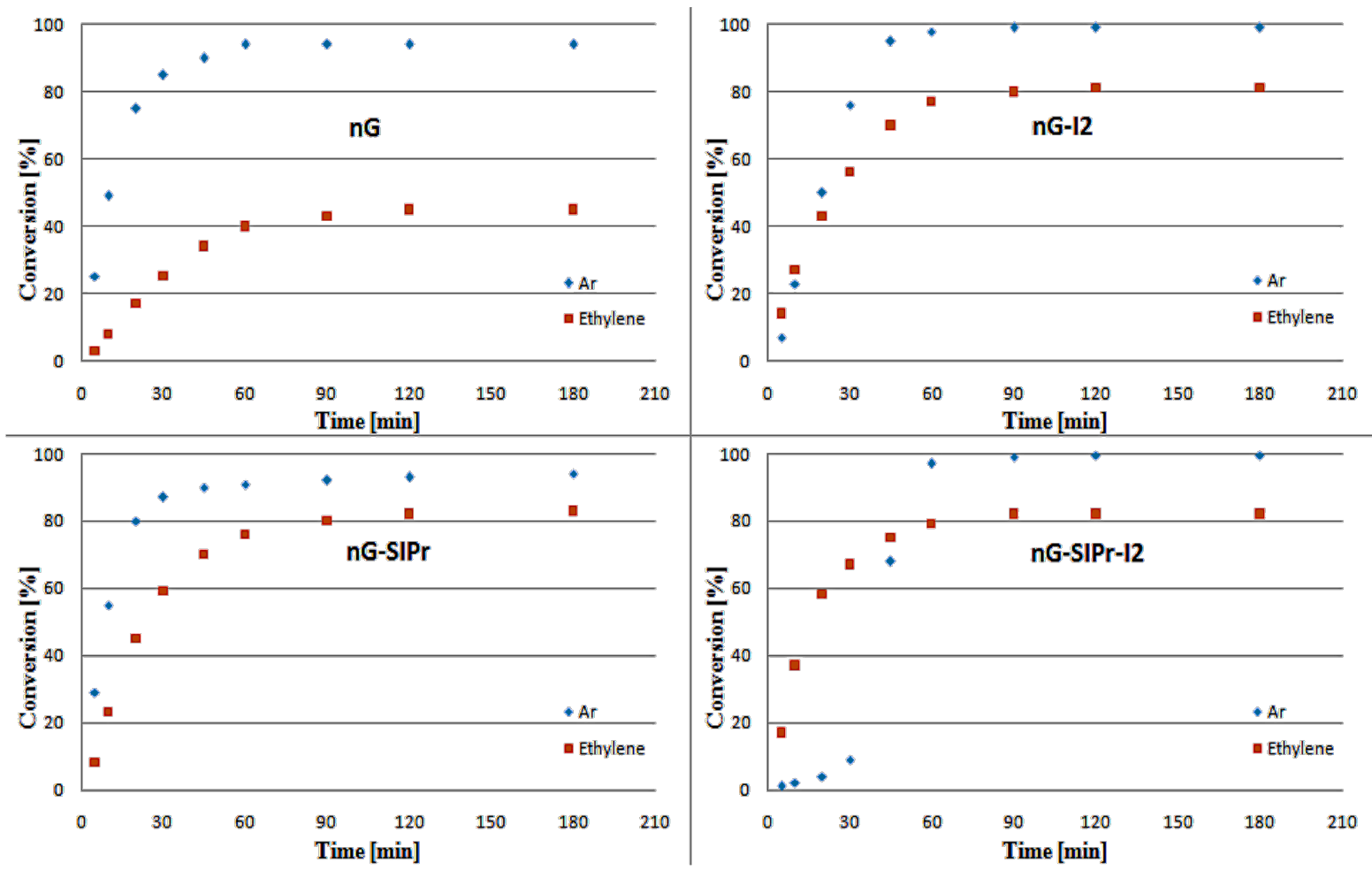

Figure 4: RCM of 1 (toluene, $0.05 \mathrm{M}, 25^{\circ} \mathrm{C}$, [Ru] $0.01 \mathrm{~mol} \%$ ): top - productive RCM and possible non-productive events; bottom - reaction profiles of tested catalysts (blue diamonds - reaction under $\mathrm{Ar}$, red squares - reaction under ethylene).

delivered $\mathbf{2}$ with poor yield, usually accompanied by significant amounts of byproducts $\mathbf{2 1}$ and $\mathbf{2 2}$. This demonstrates that large substituents in $\mathrm{N}$-heterocyclic ligands (NHC) not only increased efficiency of Hoveyda-type catalysts, but also to some extent prevented formation of ruthenium species active in non-metathetical transformations.

We decided to check whether additional steric restraints around the ruthenium center caused by iodides [32] can stabilize catalysts during OM in ACS grade solvents under air. RCM of 1 carried out in toluene was accomplished by $\mathbf{n G}$ with only $54 \%$ yield and $89 \%$ selectivity (Table 4 ). This reduced efficiency and selectivity observed in ACS grade toluene is most probably related to the small amounts of basic amines present in this solvent $[33,34]$. As anticipated, nG-SIPR performed better, giving $92 \%$ of product and $8 \%$ of isomers. We were pleased to see that nG-I2 and nG-SIPr-I2 provided over $99 \%$ of the expected product. As observed previously, nG exhibited very low activity in 2-MeTHF while nG-SIPR gave $90 \%$ of $\mathbf{2}$ which was, however, accompanied by $10 \%$ of isomers. The yield (96-97\%) and the selectivity (98\%) for both iodide analogues were noticeably better. The advantage of sterically crowded 
Table 3: Results of the macrocyclization reactions.

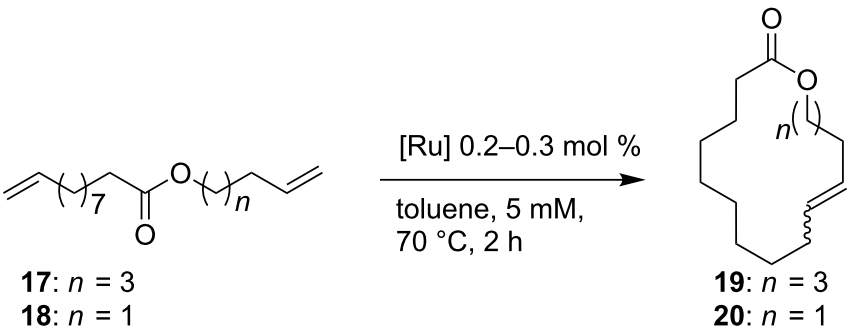

\begin{tabular}{|c|c|c|c|c|c|}
\hline Entry & $n$ & Conditions & Catalyst (mol \%) & $\begin{array}{l}\text { GC Conversion } \\
\text { (selectivity) [\%] }\end{array}$ & $\begin{array}{l}\text { GC Yield [\%] } \\
(E / Z)\end{array}$ \\
\hline 1 & 3 & active removal of ethylene & nG $(0.3)$ & $77(70)$ & $54(2.9 / 1)$ \\
\hline 2 & & & nG-12 (0.3) & $98(93)$ & $91(3.1 / 1)$ \\
\hline 3 & & & nG-SIPr (0.3) & $77(90)$ & $69(2.5 / 1)$ \\
\hline 4 & & & nG-SIPr-12 (0.3) & $90(94)$ & $85(2.3 / 1)$ \\
\hline 5 & 3 & no active removal of ethylene & nG $(0.3)$ & $5(80)$ & 4 \\
\hline 6 & & & nG-12 (0.3) & $87(89)$ & $77(2.7 / 1)$ \\
\hline 7 & & & nG-SIPr (0.3) & $8(88)$ & 7 \\
\hline 8 & & & nG-SIPr-12 (0.3) & $7(100)$ & 7 \\
\hline 9 & 1 & active removal of ethylene & nG $(0.2)$ & $72(62)$ & $45(8 / 1)$ \\
\hline 10 & & & nG-12 (0.2) & $99(82)$ & $81(8 / 1)$ \\
\hline 11 & & & nG-SIPr (0.2) & $97(68)$ & $66(9 / 1)$ \\
\hline 12 & & & nG-SIPr-12 (0.2) & $98(73)$ & $72(6 / 1)$ \\
\hline 13 & 1 & no active removal of ethylene & nG $(0.2)$ & $8(62)$ & 5 \\
\hline 14 & & & nG-12 (0.2) & $68(84)$ & $57(5 / 1)$ \\
\hline 15 & & & nG-SIPr $(0.2)$ & $5(60)$ & 3 \\
\hline 16 & & & nG-SIPr-12 (0.2) & $6(50)$ & 3 \\
\hline
\end{tabular}

Table 4: RCM of 1 in ACS-grade solvents under air. ${ }^{\text {a }}$

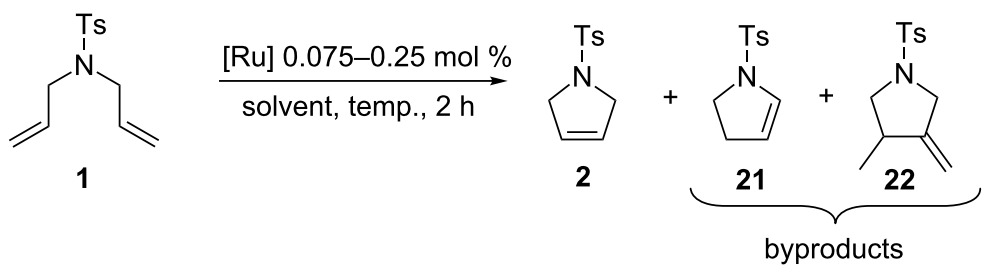

\begin{tabular}{|c|c|c|c|c|}
\hline \multirow[t]{2}{*}{ Catalyst } & \multicolumn{4}{|c|}{ GC Yield (selectivity) [\%] } \\
\hline & toluene $^{b}$ & 2-MeTHFc & $\mathrm{iPrOH}^{\mathrm{d}}$ & $\mathrm{MeOH}^{\mathrm{e}}$ \\
\hline nG & $54(89)$ & $28(97)$ & $21(72)$ & $14(88)$ \\
\hline nG-12 & $>99$ & $97(98)$ & $84(99)$ & $47(98)$ \\
\hline nG-SIPr & $92(92)$ & $90(90)$ & $77(82)$ & $46(87)$ \\
\hline nG-SIPr-I2 & $99(99)$ & $96(98)$ & $94(97)$ & $94(95)$ \\
\hline
\end{tabular}

aReactions carried out in non-degassed, non-distilled ACS grade solvents under air; ${ }^{b}[\mathrm{Ru}] 0.1 \mathrm{~mol} \%, 70{ }^{\circ} \mathrm{C} ;{ }^{\mathrm{c}}[\mathrm{Ru}] 0.25 \mathrm{~mol} \%, 40{ }^{\circ} \mathrm{C}$; $\mathrm{d}[\mathrm{Ru}] 0.075 \mathrm{~mol} \%, 70^{\circ} \mathrm{C}$; ${ }^{\mathrm{e}}[\mathrm{Ru}] 0.25 \mathrm{~mol} \%, 40^{\circ} \mathrm{C}$.

catalysts was even more pronounced when reactions were carried out in alcohols. In iPrOH $0.075 \mathrm{~mol} \%$ of $\mathbf{n G}$ gave only $21 \%$ of 2 with $72 \%$ selectivity; nG-SIPr was much more effi- cient (77\% of yield), but the selectivity was limited ( $82 \%)$. In contrast nG-I2 delivered $84 \%$ of the product with $99 \%$ selectivity, and nG-SIPr-I2 yielded $94 \%$ of 2 with $97 \%$ selectivity. 
Noteworthy is that nG-SIPr-I2 was the only catalyst able to efficiently promote RCM of $\mathbf{1}$ in methanol.

To further differentiate the tested catalysts, we performed RCM of DEDAM, which required an even higher stability of the active species. In this transformation, nG failed to give substantial amounts of the product in any solvent (Table 5). Interestingly, nG-SIPr exhibited very low efficiency in 2-MeTHF, but in other solvents ensured better yields than nG-I2. Regardless, the solvent applied, nG-SIPr-I2, was the most efficient catalyst.

$$
\text { Table 5: RCM of DEDAM in ACS-grade solvents under air. }{ }^{a}
$$

\begin{tabular}{|c|c|c|c|c|}
\hline \multirow[t]{2}{*}{ Catalyst } & \multicolumn{4}{|c|}{ GC Yield [\%] } \\
\hline & toluene $e^{b}$ & 2-MeTHFC & $\mathrm{iPrOH}^{\mathrm{d}}$ & $\mathrm{MeOH}^{\mathrm{e}}$ \\
\hline nG & 33 & 31 & 15 & 9 \\
\hline nG-12 & 77 & 98 & 76 & 31 \\
\hline nG-SIPr & 96 & 25 & 87 & 43 \\
\hline nG-SIPr-12 & 98 & 100 & 99 & 64 \\
\hline
\end{tabular}

aReactions carried out in non-degassed, non-distilled ACS grade solvents under air; ${ }^{\mathrm{b}}[\mathrm{Ru}] 0.1 \mathrm{~mol} \%, 70{ }^{\circ} \mathrm{C}$; ${ }^{\mathrm{C}}[\mathrm{Ru}] 0.25 \mathrm{~mol} \%, 40{ }^{\circ} \mathrm{C}$; $\mathrm{d}[\mathrm{Ru}] 0.25 \mathrm{~mol} \%, 70^{\circ} \mathrm{C}$; $\left.{ }^{[R u}\right] 0.75 \mathrm{~mol} \%, 40^{\circ} \mathrm{C}$.

In our final experiment we performed self metathesis of tertbutyldimethylsilyl (TBS)-protected 5-hexen-1-ol without any additives that are known to prevent double bond isomerization [35]. As expected, SM turned out to be much more challenging than RCM reactions in terms of the catalyst efficiency and selectivity (Table 6). With $1 \mathrm{~mol} \%$ of $\mathbf{n G}$ only a minor amount of $\mathbf{2 4}$ was observed in toluene and no catalytic activity was noted in 2-MeTHF. nG-SIPr performed better in these solvents, but iodide catalysts were twice as efficient and in addition, were noticeably more selective. In alcohols $2.5 \mathrm{~mol} \%$ of $\mathbf{n G}$ or nG-SIPr delivered from 9 to $19 \%$ of $\mathbf{2 4}$ with dramatically low selectivity in the range of $25-47 \%$. Application of nG-I2 or nG-SIPr-I2 resulted in the formation of $48-72 \%$ of the expected product with fair selectivity $(83-91 \%)$.

\section{Conclusion}

The iodide-containing nitro-Grela analogues exhibit improved efficiency in RCM and CM of sterically non-demanding substrates. Additional steric hindrance in the metal center proximity caused by iodides makes the 14-electron species less sensitive to small impurities, coordinative solvents (e.g., 2-MeTHF) and protic solvents. These factors lead in some cases, to dramatic improvement in the reaction(s) yield and selectivity. Increased stability of the ruthenium methylidenes generated from nG-I2 makes this catalyst especially suitable for macrocyclization of dienes with low effective molarity.

\section{Supporting Information}

\section{Supporting Information File 1}

Experimental and spectral data for nG-I2, nG-SIPr-I2 and the test reactions.

[http://www.beilstein-journals.org/bjoc/content/ supplementary/1860-5397-11-198-S1.pdf]

\section{References}

1. Grela, K. Olefin Metathesis Theory and Practice; Wiley: Hoboken, 2014.

2. Nelson, D. J.; Manzini, S.; Urbina-Blanco, C. A.; Nolan, S. P. Chem. Commun. 2014, 50, 10355-10375. doi:10.1039/C4CC02515F

\begin{tabular}{|c|c|c|c|c|}
\hline & OTBS & $\frac{[\mathrm{Ru}] 1-2.5 \mathrm{~mol} \%}{\text { solvent, } 32{ }^{\circ} \mathrm{C}, 2 \mathrm{~h}}$ & & \\
\hline \multirow[t]{2}{*}{ Catalyst } & \multicolumn{4}{|c|}{ GC Yield (selectivity) [\%] } \\
\hline & toluene $^{b}$ & 2-MeTHFb & iPrOHc & $\mathrm{MeOH}^{\mathrm{c}}$ \\
\hline nG & $13(87)$ & 0 & $19(27)$ & $19(25)$ \\
\hline nG-12 & 70 (99) & 67 (97) & 72 (91) & $48(83)$ \\
\hline nG-SIPr & $38(93)$ & $33(87)$ & $15(25)$ & $9(47)$ \\
\hline nG-SIPr-I2 & $67(97)$ & 57 (95) & $65(86)$ & $65(86)$ \\
\hline
\end{tabular}

Table 6: CM of TBS protected 5-hexen-1-ol in ACS-grade solvents under air. ${ }^{\text {a }}$

aReactions carried out in non-degassed, non-distilled ACS grade solvents under air; ${ }^{b}[\mathrm{Ru}] 1 \mathrm{~mol} \%$; ${ }^{\mathrm{C}}[\mathrm{Ru}] 2.5 \mathrm{~mol} \%$. 
3. Grubbs, R. H.; Wenzel, A. G. Handbook of Metathesis, 2nd ed.; Wiley-VCH: Weinheim, 2015; Vol. 1. doi:10.1002/9783527674107

4. Garber, S. B.; Kingsbury, J. S.; Gray, B. L.; Hoveyda, A. H. J. Am. Chem. Soc. 2000, 122, 8168-8179. doi:10.1021/ja001179g

5. Rosebrugh, L. E.; Herbert, M. B.; Marx, V. M.; Keitz, B. K.; Grubbs, R. H. J. Am. Chem. Soc. 2013, 135, 1276-1279. doi:10.1021/ja311916m

6. Marx, V. M.; Sullivan, A. H.; Melaimi, M.; Virgil, S. C.; Keitz, B. K.; Weinberger, D. S.; Bertrand, G.; Grubbs, R. H. Angew. Chem., Int. Ed. 2015, 54, 1919-1923. doi:10.1002/anie.201410797

7. Skowerski, K.; Pastva, J.; Czarnocki, S. J.; Janoscova, J. Org. Process Res. Dev. 2015, 19, 872-877. doi:10.1021/acs.oprd.5b00132

8. Nelson, D. J.; Queval, P.; Rouen, M.; Magrez, M.; Toupet, L.; Caijo, F.; Borré, E.; Laurent, I.; Crévisy, C.; Baslé, O.; Mauduit, M.; Percy, J. M. ACS Catal. 2013, 3, 259-264. doi:10.1021/cs400013z

9. Urbina-Blanco, C. A.; Leitgeb, A.; Slugovc, C.; Bantreil, X.; Clavier, H.; Slawin, A. M. Z.; Nolan, S. P. Chem. - Eur. J. 2011, 17, 5045-5053. doi:10.1002/chem.201003082

10. Gatti, M.; Vieille-Petit, L.; Luan, X.; Mariz, R.; Drinkel, E.; Linden, A.; Dorta, R. J. Am. Chem. Soc. 2009, 131, 9498-9499. doi:10.1021/ja903554v

11. Manzini, S.; Urbina-Blanco, C. A.; Slawin, A. M. Z.; Nolan, S. P. Organometallics 2012, 31, 6514-6517. doi:10.1021/om300719t

12. Sanford, M. S.; Love, J. A.; Grubbs, R. H. J. Am. Chem. Soc. 2001, 123, 6543-6554. doi:10.1021/ja010624k

13. Wappel, J.; Urbina-Blanco, C. A.; Abbas, M.; Albering, J. H.; Saf, R.; Nolan, S. P.; Slugovc, C. Beilstein J. Org. Chem. 2010, 6, 1091-1098. doi:10.3762/bjoc.6.125

14. Abbas, M.; Wappel, J.; Slugovc, C. Macromol. Symp. 2012, 311 , 122-125. doi:10.1002/masy.201000095

15. Abbas, M.; Slugovc, C. Tetrahedron Lett. 2011, 52, 2560-2562. doi:10.1016/j.tetlet.2011.03.038

16. Schrodi, Y.; Ung, T.; Vargas, A.; Mkrtumyan, G.; Lee, C. W.; Champagne, T. M.; Pederson, R. L.; Hong, S. H. Clean: Soil, Air, Water 2008, 36, 669-673. doi:10.1002/clen.200800088

17. Gillingham, D. G.; Kataoka, O.; Garber, S. B.; Hoveyda, A. H. J. Am. Chem. Soc. 2004, 126, 12288-12290. doi:10.1021/ja0458672

18. Koh, M. J.; Khan, R. K. M.; Torker, S.; Hoveyda, A. H. Angew. Chem., Int. Ed. 2014, 53, 1968-1972. doi:10.1002/anie.201309430

19. Endo, K.; Grubbs, R. H. J. Am. Chem. Soc. 2011, 133, 8525-8527. doi:10.1021/ja202818v

20. Teo, P.; Grubbs, R. H. Organometallics 2010, 29, 6045-6050. doi:10.1021/om1007924

21. Occhipinti, G.; Hansen, F. R.; Törnroos, K. W.; Jensen, V. R. J. Am. Chem. Soc. 2013, 135, 3331-3334. doi:10.1021/ja311505v

22. Guidone, S.; Songis, O.; Falivene, L.; Nahra, F.; Slawin, A. M. Z.; Jacobsen, H.; Cavallo, L.; Cazin, C. S. J. ACS Catal. 2015, 5, 3932-3939. doi:10.1021/acscatal.5b00219

23. Marciniec, B.; Rogalski, S.; Potrzebowski, M. J.; Pietraszuk, C. ChemCatChem 2011, 3, 904-910. doi:10.1002/cctc.201000376

24.Bek, D.; Gawin, R.; Grela, K.; Balcar, H. Catal. Commun. 2012, 21 , 42-45. doi:10.1016/j.catcom.2012.01.020

25. Thiel, V.; Wannowius, K.-J.; Wolff, C.; Thiele, C. M.; Plenio, H. Chem. - Eur. J. 2013, 19, 16403-16414. doi:10.1002/chem.201204150

26. Bates, J. M.; Lummiss, J. A. M.; Bailey, G. A.; Fogg, D. E. ACS Catal. 2014, 4, 2387-2394. doi:10.1021/cs500539m
27. Hamasaki, R.; Funakoshi, S.; Misaki, T.; Tanabe, Y. Tetrahedron 2000, 56, 7423-7425. doi:10.1016/S0040-4020(00)00654-2

28. Fürstner, A.; Thiel, O. R.; Ackermann, L. Org. Lett. 2001, 3, 449-451. doi:10.1021/ol0069554

29. Lysenko, Z.; Maughon, B. R.; Mokhtar-Zadeh, T.; Tulchinsky, M. L. J. Organomet. Chem. 2006, 691, 5197-5203. doi:10.1016/j.jorganchem.2006.08.031

30. Skowerski, K.; Pastva, J.; Czarnocki, S. J.; Janoscocva, J. Org. Process Res. Dev. 2015, 19, 872-877. doi:10.1021/acs.oprd.5b00132

31. Skowerski, K.; Białecki, J.; Tracz, A.; Olszewski, T. K. Green Chem. 2014, 16, 1125-1130. doi:10.1039/C3GC41943F

32. The ionic radii of chloride and iodide are $167 \mathrm{pm}$ and $206 \mathrm{pm}$, respectively; the covalent radii of chlorine and iodine are $99 \mathrm{pm}$ and $133 \mathrm{pm}$, respectively.

33. Nicola, T.; Brenner, M.; Donsbach, K.; Kreye, P. Org. Process Res. Dev. 2005, 9, 513-515. doi:10.1021/op0580015

34. Ireland, B. J.; Dobigny, B. T.; Fogg, D. E. ACS Catal. 2015, 5, 4690-4698. doi:10.1021/acscatal.5b00813

35. Hong, S. H.; Sanders, D. P.; Lee, C. W.; Grubbs, R. H. J. Am. Chem. Soc. 2005, 127, 17160-17161. doi:10.1021/ja052939w

\section{License and Terms}

This is an Open Access article under the terms of the Creative Commons Attribution License (http://creativecommons.org/licenses/by/2.0), which permits unrestricted use, distribution, and reproduction in any medium, provided the original work is properly cited.

The license is subject to the Beilstein Journal of Organic Chemistry terms and conditions:

(http://www.beilstein-journals.org/bjoc)

The definitive version of this article is the electronic one which can be found at: doi:10.3762/bjoc. 11.198 